\title{
SYNERGIC ACTION OF PENICILLIN AND SULPHATHIAZOLE IN GONORRHOEA
}

\author{
BY \\ E. R. HARGREAVES \\ Deputy County Medical Officer, Cornwall
}

The control of venereal diseases in rural areas presents certain problems and difficulties not met with in the city. The County of Cornwall, with which this paper deals, has a scattered population of 322,500 . No industrial areas exist, but there are some half dozen market towns and small seaports each with from ten to sixteen thousand inhabitants. Five clinics for the treatment of venereal diseases are established, but even so patients have to travel as much as thirty miles by indifferent bus and rail services to attend. Beds for the reception of venereal disease cases are reserved at the Royal Cornwall Infirmary, Truro, but as such accommodation is limited reliance has to be placed on efficient out-patient treatment at the clinics.

The present investigation of acute gonorrhœa was undertaken to find a treatment that could safely be employed on patients attending at once-weekly clinics and that also would give a high percentage of cures. The following three methods of treatment were investigated: (1) a single injection of 200,000 units of penicillin in oil-beeswax ; (2) sulphathiazole $25 \mathrm{~g}$. over five days, $5 \mathrm{~g}$. being given daily ; (3) a single injection of 200,000 units of penicillin in oil-beeswax on the first day, together with sulphathiazole $20 \mathrm{~g}$., over four days, $5 \mathrm{~g}$., being given daily.

In order to obtain results that were comparable in so small a number of cases, only fresh male urethral infections showing a positive culture and smear have been recorded. The three methods were used in rotation until twenty patients in each group had been treated. The results were then reviewed and subsequently all cases received

- treatment by the method that had given the best rate of cure in this preliminary trial. The penicillin preparation used was the calcium salt suspended in ethyl oleate containing 4 per cent. $w / w$ beeswax.
Penicillin

The efficacy of multiple injections of penicillin in the treatment of gonorrhœa is now well established. The Report of the Health Division of U.N.R.R.A. (1946) states that, of 12,403 male cases of gonorrhca, $94 \cdot 2$ per cent. were cured after one course of penicillin treatment and a further 4 per cent. following a second course. Laird and Fieldsend (1946), having established that 100,000 units of penicillin was the minimum satisfactory dose, carried out investigations to ascertain the optimum spacing of the injections. They concluded that five injections of 20,000 units given at two-hourly intervals gave the best result, the failure and relapse rate being only 1.5 per cent. Marshall (1945) using 100,000 units in doses of 20,000 units at three-hourly intervals, reports 84 per cent. cured.

Reports on the use of a single injection of penicillin are as yet few. Allan (1946), reported good results in a series of cases treated with a single injection of 200,000 units in aqueous solution. Batchelor and others (1946) investigated the effects of oil-beeswax suspensions of penicillin and conclude that single injections of 200,000 units of such a preparation will cure 90.2 per cent. of cases in males ; and that a second such injection will raise the percentage of cures to 95.8 per cent.

\section{Sulphonamides}

Sulphonamides, first used for the treatment of gonorrhca in 1937, proved of great value during the subsequent five years but their efficiency appears to have waned during the war years, possibly on account of the spread of sulphonamide-resistant strains of gonococci. 
Campbell (1944), in an interesting account of gonorrhœa affecting British troops in North Africa and in the central Mediterranean area, states that sulphathiazole cured 70 to 75 per cent. of cases of acute gonorrhœe in North Africa, but that in Sicily and Italy less than 25 per cent. responded to a course of 25 to $30 \mathrm{~g}$. of sulphathiazole. "As the campaign has progressed northwards in Italy and expert venereal diseases treatment units have moved forward, there has been a slight improvement in the picture, but considerably less than 50 per cent. of acute gonorrhoea cases respond to an initial course of 25 to $30 \mathrm{~g}$. of sulphathiazole, and relapses are common."

\section{Penicillin and Sulphathiazole}

Little work has as yet been published on the synergic action of penicillin and sulphathiazole against the gonococcus. In a paper on the treatment of sulphonamide-resistant cases of gonorrhœa, Lees (1946) writes : “A small series of cases were treated with sulphathiazole, 5 g. a day for five days and 30,000 units of penicillin on the fifth day. The results were not good, and we could not confirm the published reports that there was a marked synergic effect and that 100 per cent. cures could thus be achieved quickly. It was considered that such schemes of treatment were unlikely to have much further value, and the experiment was not pursued." Oaird and others (1944) have published the results of a trial of combined sulphathiazole and penicillin treatment. They gave $8 \mathrm{~g}$. of sulphathiazole on the first day and a further $4 \mathrm{~g}$. on the second day; also 50,000 units of penicillin were injected on the first day of treatment at the rate of 10,000 every three hours. In a series of 232 cases they record 95 per cent. cures.

\section{Results}

Results obtained in the preliminary trial of twenty cases in each group are shown in the Table.

In view of the excellent results obtained by the combined action of penicillin and sulphathiazole, all subsequent cases were treated by this method. A series of fifty cases has now been completed; all have responded to an initial course, and no relapses have occurred during six months' surveillance. Tests of cure were carried out after one week, one month, three months, and six months ; the first three tests included an examination of the urine by the two-glass method, together with urethral and prostatic smears and cultures. Blood for Wassermann reaction was taken at three months, and six months.

\section{Discussion}

The series of cases under review is necessarily small, but the clinical findings reported strongly suggest that penicillin and sulphathiazole exert a synergic action on the gonococcus. That such action exists against $B$. typhosus, has already been demonstrated in the laboratory by Bigger (1946) and clinically by Comerford and others (1946).

TABLE

\begin{tabular}{|c|c|c|c|}
\hline Therapy & $\begin{array}{l}\text { Penicillin } \\
200,000 \\
\text { units }\end{array}$ & $\begin{array}{l}\text { Sulphathiazole } \\
25 \mathrm{~g} .\end{array}$ & $\begin{array}{c}\text { Penicillin } \\
200,000 \text { units } \\
\text { and } \\
\text { sulphathiazole } \\
20 \mathrm{~g} \text {. }\end{array}$ \\
\hline Number of cases of acute gonorrhœa & 20 & 20 & 20 \\
\hline $\begin{array}{l}\text { Average number of days after onset of } \\
\text { symptoms before commencement of treat- } \\
\text { ment } \begin{array}{llllll}. . & . . & . & . . & . . & .\end{array}\end{array}$ & $7 \cdot 4$ & $5 \cdot 0$ & $5 \cdot 5$ \\
\hline $\begin{array}{c}\text { Number of cases clinically cured at end of } \\
\text { treatment } \\
.\end{array}$ & 16 & 13 & 20 \\
\hline Number of cases requiring further treatment & 4 & 7 & $\mathbf{0}$ \\
\hline $\begin{array}{c}\text { Percentage of cases. cured by one course of } \\
\text { treatment (surveillance } 6 \text { months) }\end{array}$ & 80 & 65 & 100 \\
\hline
\end{tabular}


I have endeavoured to obtain laboratory confirmation of synergic action of the two drugs against the gonococcus, but $I$ found it impossible to isolate a pure strain of gonococcus sufficiently virile to give trustworthy results.

\section{Summary}

A series of sixty cases of acute gonorrhœa in males have been treated by (a) single injection of penicillin in oil-beeswax (200,000 units), (b) $25 \mathrm{~g}$. sulphathiazole over five days, or (c) single injections of penicillin in oil-beeswax $(200,000$ units) plus $20 \mathrm{~g}$. sulphathiazole. The results obtained in groups (a) and (b) were in agreement with the consensus of opinion in the literature. The treatment by the combination of penicillin and sulphathiazole gave excellent clinical results ; over fifty cases have now been treated, with 100 per cent. cures. All cases in this series have now completed six months' surveillance; there have been no relapses.

\section{REFERENCES}

Allan, A. (1946). Brit. med. J., 1, 314.

Batchelor, R. C. L., Donald, W. H., and Murrell, M. (1946). Ibid., 2, 151.

Bigger, J. W. (1946). Lancet, 1, 81.

Campbell, D. J. (1944). Brit. med. J., $2,44$.

Comerford, C. H., Richmond, H., and Kay, W. W. (1946). Lancet, 2, 343.

Laird, S. M., and Fieldsend, A. B. (1946). Lancet, $1,53$.

Lees, R. (1946). Brit. med. J., 1, 605.

Marshall, J. (1945). Brit. J. vener. Dis., 21, 150.

Oard, H. C., Jorden, E. V., Nimaroff, M., and Phelan, W. J. (1944). ' Amer. J. med. Ass., 125, 323.

U N.R.R.A. (1946). Lancet, 1, 58. 